\title{
Measuring female mate choice in Cayo Santiago rhesus macaques
}

\author{
JOSEPH H. MANSON* \\ Department of Anthropology and EHB Program, 100 Rackham Bldg, The University of Michigan, \\ Ann Arbor, MI 48109-1070, U.S.A.
}

(Received 18 April 1991; initial acceptance 25 June 1991; final acceptance 8 November 1991; MS. number A6032)

\begin{abstract}
Few studies of female mate choice have been carried out among free-ranging non-human primates. To qualify as female mate choice, behaviour by oestrous females must predict the occurrence or rate of potentially fertile copulations, in comparisons between heterosexual dyads. In this paper, data are presented to show three behaviour patterns that meet this criterion in free-ranging rhesus macaques, Macaca mulatta, at the island colony of Cayo Santiago: (1) selective cooperation with male sexual solicitations (hip-grasps), (2) restoration of proximity following attacks on females by intruding males, and (3) proximity maintenance (in one of two study groups). Oestrous females maintained proximity preferentially to lower ranking males, but this appeared to reflect differences in the tactics necessary to achieve copulations with males of different dominance ranks, rather than preference for lower ranking mates. Male-oestrous female dyads showed consistency over two consecutive mating seasons in which partner was responsible for proximity maintenance. Male dominance rank was positively correlated with copulatory rate with fertile females. However, in one study group, males to whom oestrous females maintained proximity more actively had higher copulatory rates with fertile females, independent of the effects of male dominance rank.
\end{abstract}

Female mate choice, a potentially powerful selective force (see reviews in Bradbury \& Andersson 1987), has received little systematic attention in nonhuman primates (Small 1989). In this paper, I use data from free-ranging rhesus macaques, Macaca mulatta, to address three questions. First, what quantifiable female behaviour patterns predict copulation rates of heterosexual dyads? Second, are females choosing particular males, or following a promiscuous mating strategy? Third, does female mate choice affect male copulatory success independently of the effects of inter-male competition?

Halliday (1983, page 4) defines mate choice as 'any pattern of behaviour, shown by members of one sex, that leads to their being more likely to mate with certain members of the opposite sex than others'. Thus, a behaviour pattern of oestrous females can be considered a mate choice signal if the occurrence or rate of the behaviour pattern, compared across heterosexual dyads, predicts the occurrence or rate of potentially fertile copulations. Demonstrating this relationship is necessary because otherwise, for instance, a behaviour that *Present address: 350 Mts. E. Del I.C.E., Bagaces, Guanacaste, Costa Rica. appears to be a manifestation of sexual aversion (e.g. persistently walking away from a male) may also be interpreted as a female tactic for testing male quality. Female behaviour need not lead to immediate copulations to qualify as mate choice. For instance, a female behaviour toward a particular male may have the immediate effect of altering his behaviour toward her, leading eventually (perhaps several days later) to an increased probability of a copulation occurring between them.

Mate choice is distinguished from mate preference, which 'denotes a disposition or propensity that an individual possesses whether or not it is exercised ... female mating preferences can only be observed by observing female choice under conditions where the object of the preference is separated from other factors that may influence its expression' (Heisler et al. 1987, pp. 99-100). Thus, mate preferences can be measured only under experimentally controlled conditions. Purely observational studies can produce data on female choice, but inferences about underlying preferences must remain speculative.

Demonstrating which patterns of female behaviour signal mate choice in a species provides a means of addressing other questions. In this 
Table I. Compositions of study groups by age sex class

\begin{tabular}{lccccc}
\hline & \multicolumn{2}{c}{ Group Q } & & \multicolumn{2}{c}{ Group T } \\
\cline { 2 - 3 } \cline { 5 - 6 } \multicolumn{1}{c}{ Age-sex class } & June 1988 & June 1989 & & June 1988 & June 1989 \\
& & & & & \\
\hline Adult males & $25(4)$ & $24(6)$ & & $31(3)$ & $37(7)$ \\
Subadult males & $6(5)$ & $3(3)$ & & $6(3)$ & $5(5)$ \\
Adult females & 30 & 36 & & 21 & 27 \\
Adolescent females & 7 & 6 & & 6 & 4 \\
Juveniles and infants & 58 & 74 & & 40 & 53 \\
Total & 126 & 142 & & 104 & 126 \\
\hline
\end{tabular}

Adult males: $>4.5$ years old; subadult males: 4.5 years; adult females: $>3.5$ years; adolescent females: 3.5 years; juveniles and infants: males $<4.5$ years plus females $<3.5$ years. Two males transferred from group $Q$ to group $T$ during the 1988 mating season and were counted in both groups. Parentheses contain numbers of natal males. All females were natal (see Sade 1972; Drickamer \& Vessey 1973). Natal individuals were in matrilines (three in group $Q$, two in group $T$ ), ranked by dominance status (see Sade 1967).

paper, I examine (1) whether females use mate choice criteria or follow a promiscuous mating strategy (see Hardy 1979; Small 1988, 1990) and (2) whether female choice and inter-male competition independently affect male mating success.

'Promiscuity' may be defined as following the rule of thumb that 'maximizes the number of copulatory partners', in contrast to mate choice rules of thumb such as 'copulate with the male in your group that ranks highest in attribute $x$ '. These are logical endpoints of a continuum. In multi-male groups, real-life rules of thumb governing female mating strategies may take intermediate forms such as 'copulate with all males in your group that rank above threshold level $y$ in attribute $x$ '.

Female mate choice behaviour and criteria have been demonstrated in two non-human primate species under free-ranging conditions. Janson (1984) showed that wild oestrous female brown capuchins, Cebus apella, maintained spatial proximity preferentially to the alpha male, and that the alpha male experienced almost all of the matings with fertile females. Huffman $(1987,1991)$ found that provisioned, free-ranging Japanese macaques, Macaca fuscata, had higher than expected frequencies of high-ranking and older males' sexual solicitations rejected by oestrous females, and that middle-ranking males experienced higher (estimated) reproductive success than high-ranking males.
Previous studies of rhesus macaque mating behaviour have focused on the hypothesized correlation between male dominance rank and reproductive success (Altmann 1962; Conoway \& Koford 1964; Kaufmann 1965; Drickamer 1974; Chapais 1983; Hill 1987; McMillan 1989), and have produced conflicting results. Variance in male reproductive success, not associated with dominance rank, may be explained by female choice, and secondarily by variance in male courtship intensity (Chapais 1983). Most investigators cited above reported anecdotally that rhesus females sometimes 'sneak off' to copulate with lower ranking males.

\section{SUBJECTS AND METHODS}

\section{Study Species and Site}

The subjects of my study were 65 adult ( 4.5 years and older) female rhesus macaques of two social groups (groups T and Q) on Cayo Santiago, a 15-ha island $1 \mathrm{~km}$ off the southeast coast of Puerto Rico (Table I). Rhesus macaques are mildly dimorphic in body size (males are 10-20\% larger than females), but males' canine teeth are about twice the size of females' (Harvey et al. 1978). During the 4-6 month mating season, females undergo oestrous cycles of approximately 30 days, during which they are sexually active for approximately 2 weeks. 
The monkeys of Cayo Santiago are provisioned and are trapped annually for identification marking. A bi-weekly census of the entire population updates a database of births, deaths, inter-group transfers, and group fissions covering the entire period since 1956. Periodic removal of entire social groups keeps the population between approximately 600 and 1400 individuals. Otherwise, the monkeys are free-ranging and are not handled or interfered with (for more information about Cayo Santiago management and history, see Altmann 1962; Sade et al. 1977; Rawlins \& Kessler 1986).

Social groups on Cayo Santiago range in size from 50 to 300 animals, in contrast to the $10-140$ range observed in wild and feral rhesus on the Indian subcontinent (e.g. Malik et al. 1984; Melnick et al. 1984). Adult sex ratios within groups are approximately 1:1 at Cayo Santiago, whereas in groups on the subcontinent females outnumber males 2-3:1.

\section{Measures and Definitions}

Behavioural endocrinological studies of captive rhesus macaques (Catchpole \& van Wagenen 1978; Gordon 1981) show that ovulation occurs during the 4 days preceding the 'attractiveness breakdown' (Chapais 1983); i.e. the sharp decrease (usually from 1 day to the next) in the female's sexual attractiveness. The attractiveness breakdown is recognizable by either the end of all sexual activity, or less commonly, the beginning of a 1- to 2-day period culminating in the end of all sexual activity and characterized by the (1) marked decrease in proceptive behaviour, (2) complete cessation of following and courtship by high-ranking males, and (3) toleration by these males of occasional copulations with low-ranking males in plain view (behaviour that would have provoked male aggression earlier in the oestrous period). The 4 days preceding the attractiveness breakdown will be called the peri-ovulatory period. Rhesus macaques are series mounters. Mating pairs engage in up to 100 non-ejaculatory mounts with intromission before the final ejaculatory mount, discernible by a characteristic pause and rigid posture by the male. I defined mount series culminating in ejaculation as 'copulations'. All analyses in this paper that use copulatory rate as a variable refer to copulations as defined here; incomplete mount series are not included. Because rhesus macaque females do not exhibit reliable morphological signs of oestrus, I regarded a female as being in oestrus from the day she was first seen in a mount series, or with a mating plug (coagulated ejaculate on her perineum), until the day after her attractiveness breakdown.

A dominance interaction was scored whenever one animal 'supplanted' another (approached and took its spot immediately after the approached animal vacated it) or when the approach of one animal caused another to 'grimace' (retract the lips and cheeks, exposing the teeth), 'cower' (lean downward and away from the approaching animal), or flee. I ascertained male dominance relationships by arranging males in matrices showing winners of dominance interactions along one axis and losers along the other.

An 'approach' was scored when one animal decreased the distance between itself and another animal by at least $0.5 \mathrm{~m}$ and stopped or sat, with the final distance between them being less than $4 \mathrm{~m}$. A 'leave' was scored when one animal increased the distance between itself and another animal by at least $0.5 \mathrm{~m}$, with the initial distance between them being less than $4 \mathrm{~m}$. Approaches and leaves taking place at the artificial drinking stations were excluded from analyses, as were 'leaves' during chases.

For each male-oestrous female dyad in which the sum of observed approaches and leaves was at least 10, I calculated Hinde's index (Hinde \& Atkinson 1970 ) by subtracting the proportion of all female leaves within the dyad from the proportion of all female approaches with the dyad. This index measures responsibility for maintaining spatial proximity. Its value can vary from -1.00 (the male is entirely responsible for maintaining proximity) to +1.00 (the female is entirely responsible for maintaining proximity). The cut-off of 10 summed approaches and leaves, set arbitrarily before data were analysed, increases the reliability of Hinde's index as a measure of dyadic relationships.

A 'consortship' was any male-oestrous female dyad in which the male was the female's nearest adult male neighbour in six out of 10 instantaneous samples during one 30 -min sampling block. Consort pairs were not necessarily observed to engage in sexual behaviour, nor were they assumed to have done so in any of the hypotheses or data analyses in this paper. I used the concept of 'consortship' merely to control for variation between heterosexual dyads in the amount of time spent in spatial proximity. An 'escalated attack' was scored whenever a male chased or bit an oestrous female. A 
'sexual refusal' was scored when a female responded to a male's 'hip-grasp' (grasping the female's hips with both hands from behind) by refusing to 'present' (stand up to be mounted) to begin a mount series. Females refused by either remaining seated or moving away.

I obtained the following data from the Cayo Santiago long-term database for each individual in both study groups: (1) age in years, (2) matriline (for females and natal males only), and (3) for males, breeding tenure in months (since entering the group for immigrants, and since June of the male's fifth year for natal males).

\section{Data Collection and Analysis}

One to four observers collected data on 162 days during one complete mating season (June-October 1988) and 7 weeks of a second mating season (JuneAugust 1989). Ad libitum (Altmann 1974) observations provided information about dominance relationships and cycling females' reproductive states. We conducted 2-h focal individual follows (Altmann 1974), divided into 30-min sampling blocks with no more than $5 \mathrm{~min}$ between them, on females chosen randomly from those judged to be in oestrus on the preceding day. Data from uncompleted 2-h follows were used in the analyses described here, except for uncompleted 30-min sampling blocks, which were discarded. During follows, we used checksheets to record all approaches and leaves, and all occurrences of 54 patterns of social behaviour, displayed by or directed towards the focal female. We also recorded the female's current activity, nearest adult male neighbour, and other adult neighbours within $10 \mathrm{~m}$ every $3 \mathrm{~min}$ on an instantaneous basis. Follows were temporarily discontinued when focal subjects entered the fenced-in feeding corrals.

To ensure inter-observer reliability, all observers were required to meet a standard of $90 \%$ concordant records with mine, over four consecutive 30min focal follows. Data collected during these test sessions were not analysed.

Sample sizes (number of dyads) vary in the analyses described below because all variables of interest could not be calculated for every dyad. Because I selected focal subjects randomly, some females were not sampled at all during their periovulaory periods, and therefore no data are available on peri-ovulatory copulatory rates with any males for these females.
Significance of resuits was determined using nonparametric statistical tests. Kendall's partial correlation significance levels are from Maghsoodloo (1975) and Maghsoodloo \& Laszlo Pallos (1981). All tests are two-tailed.

\section{RESULTS}

We collected a total of $716 \mathrm{~h}$ of focal data on oestrous females. Of these, $59 \mathrm{~h}$ of focal data collected on 14 females in August 1989 were discarded from these analyses because the study ended before the end of the focal females' oestrous periods, raising problems of data censorship (truncation). Thus, $657 \mathrm{~h}$ of focal data on 48 oestrous females $(\bar{X} \pm \mathrm{SD}=$ $13.8 \pm 16.0 \mathrm{~h} / \mathrm{female}$ ) were available for analysis. During these observations, we observed 229 copulations.

\section{Male Dominance Relationships}

Adult males ( 5.5 years and older) from both groups showed linear dominance hierarchies in 1988 and 1989, as indicated by the dominance matrices that I constructed; i.e. all observed interactions were on the same side of the diagonal. The exact position of most males in each hierarchy could be determined, but the dominance relationships of some dyads of low-ranking males could not be determined because we observed no interactions between the two animals. For analytical purposes, I assigned males of uncertain dominance rank (group Q 1988: $2 / 25=8.0 \%$; group Q 1989: $5 / 24=$ $20 \cdot 8 \%$ group T $1988: 12 / 31=38 \cdot 7 \%$; group T 1989 ; $10 / 37=27 \cdot 0 \%$ ) a rank that was the median rank of all the males of uncertain rank in their social group. Subadult (4.5-year-old) males had unstable ranks that were highly dependent on the presence of allies (usually kin). Adult male ranks remained stable from 1988-1989, whereas two subadult natal males improved their status considerably between the two mating seasons. In the analyses that follow, male dominance rank is expressed as the proportion of males dominated within the social group.

\section{Mate Choice Behaviour}

\section{Sexual refusals}

I classified all male-oestrous female dyads in which at least one hip-grasp was observed during focal observation ( $N=120$ in $1988 ; N=105$ in 1989) according to the proportion of hip-grasps at the start of a mount series that elicited a female sexual refusal. Combining data from all males: $34.6 \%$ of 


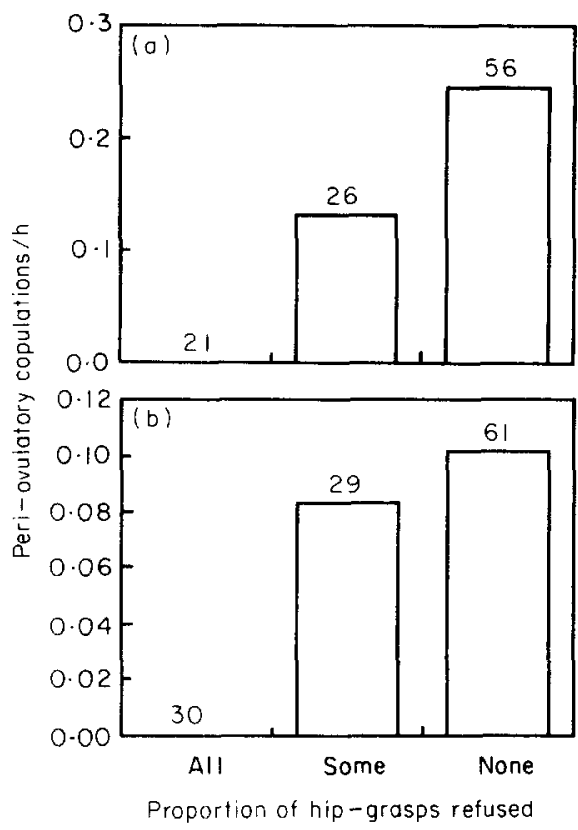

Figure 1. Copulations per hour of peri-ovulatory focal female observations in relation to the proportion of the male's hip-grasps refused by the female. Sample sizes (number of dyads) are given. (a) 1988; (b) 1989.

such hip-grasp attempts (averaged over females) elicited refusals in 1988 , and $37.5 \%$ elicited refusals in 1989. Hip-grasps were rarely observed in most dyads, so I treated 'refusal proportion' as a categorical variable (All, Some, or No hip-grasps refused) rather than a ranked or continuous variable. Because of small sample sizes, I combined data from groups $T$ and $Q$ to test whether sexual refusals were associated with peri-ovulatory copulation rate. In both 1988 and 1989, dyads in which no hip-grasps were refused had the highest peri-ovulatory copulation rates, followed by dyads in which some hipgrasps were refused, and then dyads in which all hip-grasps were refused (Fig. 1; 1988: KruskalWallis test: $H=12.333, d f=2, P<0.01 ; 1989: H=$ $8 \cdot 316, d f=2, P<0.02)$. When dyads were divided by social group, trends were in the same direction for both groups in both years, but differences were significant only in group $\mathrm{Q}$. Thus, females chose mates by cooperating selectively with certain males' hip-grasp attempts.

\section{Proximity restoration following escalated attack}

Oestrous females suffered escalated attacks by males at an average rate of 0.44 attacks/h in the
1988 mating season and $0 \cdot 26$ attacks/h in the 1989 mating season (means of individual females' rates). Most attacks occurred while the female's nearest adult male neighbour was (1) subordinate to the attacker or (2) of a different social group from the female (Manson 1991). For each male attack on a female that was accompanying another male, I determined which male the female approached first after the attack: the attacker or the male she had been with at the time of the attack. In $28 \%(17 / 61)$ of these attacks in 1988 and $18 \%(14 / 76)$ of these attacks in 1989, the female did not approach either male before the end of the focal follow, and I discarded these cases from this analysis. I assigned each male-oestrous female dyad that suffered one or more attacks to one of two categories: if, after most observed attacks, the female either approached the male of the dyad before approaching the attacker, or approached the male of the dyad but did not approach the attacker, the dyad was a 'restoration' dyad. If, after most observed attacks, the female either approached the attacker before approaching the male of the dyad, or approached the attacker but did not approach the male of the dyad, the dyad was a 'non-restoration' dyad. Because of small sample sizes, I combined data from groups $\mathrm{T}$ and $\mathrm{Q}$ to test whether proximity restoration was associated with peri-ovulatory copulation rate. Only one dyad suffered an attack by another male in both mating seasons. Using the mean of 1988 and 1989 peri-ovulatory copulation rates for this dyad, which was a restoration dyad in both mating seasons, combined data from 1988 and 1989 showed that restoration dyads had higher peri-ovulatory copulation rates than non-restoration dyads (Mann-Whitney $U$-test, $U=365 \cdot 5, N_{1}=37, N_{2}=$ $27, P=0.0038$ ). When I divided dyads by year and social group, trends were in the same direction, but non-significant, in group $Q$ in both years and in group $T$ in 1988. In group $T$ in 1989 , all five dyads (one restoration, four non-restoration) had periovulatory copulation rates of zero. Thus, following male escalated attacks, females exercised mate choice by selectively restoring proximity to certain males.

\section{Proximity maintenance}

In group $Q$ in both mating seasons, Hinde's index (i.e. female responsibility for proximity maintenance) was positively correlated with periovulatory copulation rate (1988: Kendall's $\tau=$ 
$0 \cdot 197, N=77$ dyads, $P=0.011 ; 1989: \tau=0 \cdot 226$, $N=139, P=0.00008)$. These variables were not correlated in group $T$ in either mating season (1988: $\tau=-0.107, \quad N=93, \quad P=0.129 ; 1989: \tau=0.005$, $N=31, P>0 \cdot 50$ ).

Female proximity maintenance also correlated inversely with sexual refusals, i.e. pairs with higher proportions of sexual refusals were characterized by lower levels of female proximity maintenance. Dyads with higher proportions of sexual refusals had lower Hinde's indices (1988: Kruskal-Wallis test: $H=23.059, N_{1}=14, N_{2}=29, N_{3}=64, d f=2$, $P<0.001$; 1989: $H=17.894, N_{1}=15, N_{2}=29, N_{3}=$ 57, $d f=2, P<0.001)$. Thus, selective proximity maintenance was a mate choice signal in one study group (see Discussion for consideration of alternative hypotheses and inter-group differences).

\section{Female Proximity Maintenance and Male Dominance Rank}

The Hinde's indices calculated above were averaged to give males with at least one index a mean Hinde's index (MHI). These males comprised 65\% of group Q males in 1988, 68\% of group T males in 1988 , and $81 \%$ of group Q males in 1989 . Because only eight of $27(29.6 \%)$ adult females from group $T$ completed oestrous periods in 1989 before the end of the study we collected only $69 \cdot 5 \mathrm{~h}$ of usable focal data; only $35 \%$ of group $\mathrm{T}$ males in that mating season had at least one Hinde's index calculated (i.e. had at least 10 summed approaches and leaves with at least one oestrous female). I excluded dyads of matrilineally related animals from this analysis, because (1) theoretically they are expected to have lower Hinde's indices, and (2) they had significantly lower Hinde's indices than unrelated dyads involving natal males (Manson 1991). In group $Q$ in both years, and in group $T$ in 1988, higher ranking males had lower MHIs (i.e. oestrous females maintained proximity preferentially to lower ranking males) (Fig. 2; group Q 1988: Kendall's $\tau=-0.561, N=20$ males, $P=0.0006$; group Q 1989: $\tau=-0.463, N=$ 22, $P=0.0026$; group T 1988: $\tau=-0.412, N=25$, $P=0.004$; group T 1989: $\tau=-0.273, N=12, P=$ $0 \cdot 217$ ). Dominance rank exerted a negative effect on MHI independently of the effects of male breeding tenure and age, which were sometimes positively correlated with dominance rank. Partial correlation coefficients (Kendall's $\tau$ ) between male dominance rank and MHI, controlling for male (1) age, (2) breeding tenure, and (3) age plus breeding tenure were significantly negative $(P<0 \cdot 05)$ in group $T$ in 1988 and in group $Q$ in both years, except when male age plus breeding tenure were controlled for in group $Q$ in $1988(\tau=-0 \cdot 30$, $P<0 \cdot 10$ ). The negative effect of male dominance on MHI was not attributable solely to the behaviour of females of a particular age or dominance status (matriline). I assigned each male an MHI based only on his Hinde's indices with females of a particular age class or matriline (Table II). Although there appeared to be a slight tendency for younger and lower ranking females to maintain proximity more actively to lower ranking males, no category of females showed a trend in the opposite direction (i.e. for greater proximity maintenance toward higher ranking males).

The negative correlations between male dominance rank and female proximity maintenance resulted from female tendencies preferentially to approach lower ranking males, not from female tendencies to preferentially leave higher ranking males. For each male with at least one Hinde's index, I calculated the mean (over females) proportion of female approaches (MPFA) and the mean (over females) proportion of female leaves (MPFL). In group $Q$ in both years, and group $T$ in 1988, MPFA was negatively correlated with male dominance rank (group Q 1988: $\tau=-0 \cdot 540, N=20$ males, $P=0.0009$; group Q 1989: $\tau=-0.467, N=$ 22, $P=0.0024$; group T 1988: $\tau=-0.448, N=25$, $P=0.0018$ ), whereas MPFL was not correlated with dominance rank (group $Q$ 1988: $\tau=0.241$, $P=0.136$; group $Q$ 1989: $\tau=0 \cdot 239, P=0 \cdot 119$; group T 1988: $\tau=0 \cdot 190, P=0 \cdot 184)$.

These results suggest that females do not necessarily prefer lower ranking mates, but may use different tactics to achieve copulations with males of different dominance ranks. To mate with a lower ranking male, the female must approach the male, because the male is inhibited from approaching her by the presence of higher ranking courting males. But to mate with a high-ranking male, a female can wait for him to approach her (see Discussion). Thus, each male's MHI relative to his dominance rank, is an appropriate measure of his overall sexual attractiveness. This can be expressed as the residual of the regression of $\mathrm{MHI}$ on male dominance rank.

\section{Consort Grooming}

Consort pairs (defined above) groomed frequently, yet there was considerable variation in 


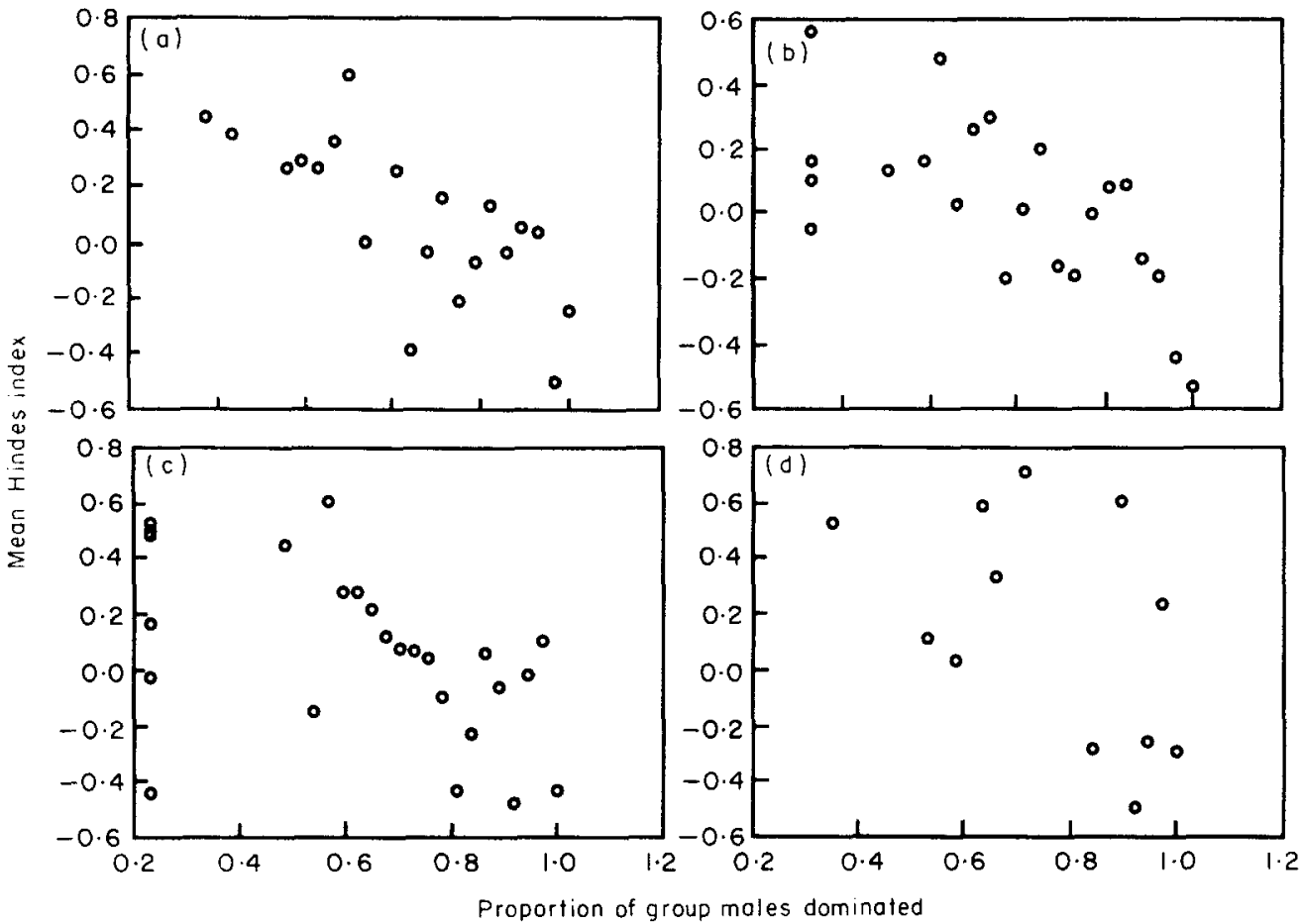

Figure 2. Mean Hinde's index in relation to male dominance rank (proportion of group males dominated). (a) Group Q 1988; (b) group Q 1989; (c) group T 1988; (d) group T 1989. Note difference in scale for $Y$-axis in (b).

Table II. Correlations (Kendall's $\tau$ ) between male dominance rank and mean Hinde's index

\begin{tabular}{ccccccc}
\hline & \multicolumn{3}{c}{ Female age (years) } & & \multicolumn{2}{c}{ Matriline rank } \\
\cline { 2 - 3 } & $11+$ & $7-10$ & 4.6 & & High & Low \\
\hline Group Q 1988 & & & & & \\
$N$ & 19 & 10 & 18 & & 9 & 16 \\
$\tau$ & -0.33 & -0.60 & -0.41 & & -0.33 & -0.68 \\
$P$ & 0.05 & 0.014 & 0.02 & & 0.21 & 0.0002 \\
Group T 1988 & & & & & \\
$N$ & 12 & 18 & 20 & & 12 & 21 \\
$\tau$ & -0.32 & -0.52 & -0.30 & & -0.24 & -0.55 \\
$P$ & 0.15 & 0.003 & 0.07 & & 0.26 & 0.0005 \\
Group Q 1989 & & & & & \\
$N$ & 17 & 10 & 21 & & 9 & 20 \\
$\tau$ & -0.20 & -0.32 & -0.56 & & -0.56 & -0.50 \\
$P$ & 0.26 & 0.21 & 0.0004 & & 0.035 & 0.002 \\
\hline
\end{tabular}

$N$ : number of males that had $10+$ summed approaches and leaves with at least one female of that age class or matriline; $\tau$ : Kendall rank correlation coefficient. Females of the middle-ranking lineage of group $\mathrm{Q}(N=2$, both mating seasons) were excluded from this analysis. 
which member of the pair did most of the grooming. Female grooming rate $(\mathrm{min} / \mathrm{h}$, calculated from the instantaneous samples) was not correlated with peri-ovulatory copulation rate for either group in 1988 or 1989 (group Q 1988: $\tau=0 \cdot 149, N=35$ consort dyads, $P=0 \cdot 208$; group Q 1989: $\tau=0 \cdot 119, N=$ 63, $P=0.168$; group T 1988: $\tau=0.035, N=38$, $P>0.50$; group T 1989: $\tau=0.091, N=21, P>0.50$ ).

\section{Numbers of Mates and Copulations Per Female}

The hourly copulation rate $(\bar{X} \pm \mathrm{SE})$ of focal females was $0.54=0.06$ during the 1988 mating season and $0.30 \pm 0.05$ during the 1989 mating season. Assuming $12 \mathrm{~h} /$ day available for sexual activity (probably a conservative estimate), this translates to approximately 50-90 estimated copulations in a 14-day oestrous period. The number of copulations actually observed per estrous period was much smaller (1988: $\bar{X} \pm \mathrm{SE}=4 \cdot 44 \pm 0 \cdot 32 ; 1989$ : $9 \cdot 08 \pm 1 \cdot 15)$. Including copulations we observed during ad libitum data collection, females averaged $(\bar{X} \pm \mathrm{SE}) 3.00 \pm 0.25$ copulatory partners (range $=1-$ 7) per oestrous period in 1988 , and $4 \cdot 16 \pm 0.51$ (range $=0-9$ ) in 1989. During the 1989 mating season, when four females were focal subjects for $51-67 \mathrm{~h}$, number of focal hours was positively correlated with number of observed copulatory partners, including partners observed during ad libitum observation (Kendall's $\tau=0.371, N=25$ females, $P=0.009$; regression analysis, $r^{2}=0 \cdot 274$ ). No significant correlation between number of focal hours and number of copulatory partners was found in $1988(\tau=0 \cdot 164, N=39, P=0 \cdot 142$; regression analysis, $r^{2}=0 \cdot 035$ ), when no female was a focal subject for more than $21.5 \mathrm{~h}$, or in 1989 after removing the four most frequently observed females from the analysis. These results imply that if any female were followed for a long enough period, she would be observed to mate with a larger number of males than the number we actually observed during the limited set of observations.

\section{Consistency in Proximity Maintenance between Mating Seasons}

Hinde's indices were consistent within dyads between consecutive mating seasons. In the 41 nonmatrilineally related oestrous female-male dyads, with at least 10 summed approaches and leaves in both mating seasons, 1988 Hinde's index was significantly correlated with 1989 Hinde's index
(Kendall's $\tau=0.350, P=0.0014$ ) even after effects of male (1989) dominance rank were controlled for (partial $\tau=0 \cdot 278, P=0.012$ ). In other words, individual females showed similar degrees of proximity maintenance toward the same males in different mating seasons, even after controlling for the effect of male dominance rank on proximity maintenance.

\section{Female Proximity Maintenance and Putative Male Reproductive Success}

The best estimate available from this data set of individual adult male single-year reproductive success (mean peri-ovulatory copulation rate, averaged over all females in the social group on whom peri-ovulatory focal data were collected) was positively correlated with dominance rank in both years in both groups (group Q 1988: $\tau=0 \cdot 325, N=25$ males, $P=0.023$; group $Q$ 1989: $\tau=0.355, N=24$, $P=0.015$; group T 1988: $\tau=0.330, N=31, P=$ 0.009; group T 1989: $\tau=0 \cdot 38, N=37, P=0.001$ ). However, the residual of the regression of $\mathrm{MHI}$ on male dominance rank (i.e. relative $\mathrm{MHI}$ ) was also positively correlated with mean peri-ovulatory copulation rate in group $Q$ in both years (1988: $\tau=0.391, N=19$ males, $P=0 \cdot 019 ; 1989: \tau=0 \cdot 379$, $N=21, P=0.016$ ). Thus, female proximity maintenance in one study group had a positive effect on putative male reproductive success, independent of male dominance rank.

\section{DISCUSSION}

\section{Mate Choice Behaviour}

In this study of free-ranging oestrous female rhesus macaques, three patterns of behaviour qualified as measures of mate choice: (1) resistance of some males' mating solicitations (hip-grasps); (2) selective re-establishment of proximity to some males following aggressive harassment by higher ranking males; and (3) preferential proximity maintenance (in one study group, see below). Female Japanese macaques also exercised mate choice using behaviour patterns (1) and (2) (Huffman 1987, 1991). A fourth hypothesized mate choice behaviour pattern, grooming of consorts, was not correlated with peri-ovulatory copulation rate.

Given the occurrence of male escalated attacks against oestrous females, the positive correlation between Hinde's index and peri-ovulatory copulation rate in one social group may represent female 
response to male aggressive 'herding', rather than mate choice. Male herding of females occurs in hamadryas baboons, Papio hamadryas (Kummer 1968) and chimpanzees, Pan troglodytes (Tutin 1979; Goodall 1986). However, in my study, most attacks were directed by higher ranking males against females accompanying lower ranking males (Manson 1991), leading to the prediction that if female proximity maintenance were a response to herding, females should maintain proximity preferentially to higher ranking males. A female could escape the herding attempts of a low-ranking male by approaching and maintaining proximity to a higher ranking male, whereas she could be compelled to respond to a high-ranking male's herding attempts by maintaining proximity to him. Yet females of all age and rank categories maintained proximity preferentially to lower ranking males, falsifying the 'herding' hypothesis. By maintaining proximity to low-ranking males, females incurred the cost of more frequent male attacks (Manson 1991).

A second alternative is that the causal relationship between female proximity maintenance and copulation rate is reversed: that males vary in their mating capacity and that females seek proximity to those males that can deliver potentially fertilizing ejaculates at higher rates (Small 1988). Although this hypothesis cannot be quantitatively falsified with this data set, it is inconsistent with our observation that males frequently masturbated to ejaculation after following and unsuccessfully courting an oestrous female for up to $2 \mathrm{~h}$. Furthermore, the high adult sex ratio and relatively long mating season of Cayo Santiago rhesus macaques create conditions under which sperm scarcity is unlikely (M. Small, personal communication).

\section{Inter-group Differences}

In group Q, dyadic Hinde's index was positively correlated with peri-ovulatory copulation rate in both years of this study. In group T, however, there was a non-significant negative relationship between these two variables in 1988 , and no relationship in 1989. This difference between the groups may stem from differences in group size and composition. In both years, group $\mathrm{T}$ had a higher adult sex ratio and a smaller absolute number of adult females than group Q (Table I). Thus, all else being equal, sequestering and monopolization of fertile females by high-ranking males was easier in group $\mathrm{T}$ than in group Q (see Berenstain \& Wade 1983). In other words, group $\mathrm{T}$ females may have attempted to exercise mate choice in the same way as group $Q$ females (selective proximity maintenance), but were prevented from completing copulations with preferred males because they were persistently followed by high-ranking non-preferred males (see Introduction for discussion of mate choice versus mate preference).

\section{Male Dominance Rank and Female Proximity Maintenance}

Females preferentially maintained proximity to lower ranking males. Whether females prefer lower ranking mates to higher ranking mates, however, is less clear. The finding that females approached lower ranking males more frequently, but did not leave them any less frequently, than higher ranking males is consistent with the following hypothesis: oestrous females must use different tactics to achieve copulations with males of different dominance ranks. To mate with a lower ranking male, the female must approach the male, because the male is inhibited from approaching her by the presence of higher ranking courting males. But to mate with a high-ranking male, a female can wait for him to approach her. Thus, females may simply be trying to copulate with as many males as possible, rather than seeking copulations with low-ranking males specifically. Their efforts to copulate with subordinate males may be more vigorous than their efforts to copulate with dominant males merely because of differential accessibility of low-versus high-ranking mates.

\section{Choice and Promiscuity}

Data presented here suggest that rhesus females copulate with a large number of partners in each oestrous period, based on extrapolation from the reported correlation between the amount of focal observation and the number of observed copulatory partners. This is consistent with the hypothesis (Small 1988, 1990) that females are following a promiscuous strategy.

However, over the two mating seasons of my study, male-oestrous female dyads showed consistency in which partner was responsible for proximity maintenance, independently of male dominance rank. The promiscuity hypothesis cannot account for this result. Female choice for relatively stable (presently unknown) male traits, independent of male dominance rank, is apparently a component 
of a mixed female mating strategy that incorporates elements of both choice and promiscuity. Shortterm stability in female mate choice (as in Japanese macaques: Fedigan \& Gouzoules 1978; Huffman 1991) does not necessarily imply long-term stability. Suggestive evidence from rhesus macaques (Manson 1991) and compelling evidence from Japanese macaques (Takahata 1982a, b; Huffman 1987, 1991) indicates that females develop sexual aversions to males that have been in their social group for 3-4 years or longer. Barbary macaque, M. sylvanus, females, in oestrus, change copulatory partners in rapid succession (Taub 1980; Small 1990), apparently following a more promiscuous mating strategy than rhesus or Japanese macaques.

\section{Effects of Female Choice on Putative Male Reproductive Success}

In one social group, female choice (proximity maintenance) increased putative male reproductive success independently of the effects of male dominance rank on putative reproductive success. This result implicates female choice as a potentially powerful selective force among rhesus macaques.

\section{Possible Effects of the Study Site}

The unusually large groups and high adult sex ratios of Cayo Santiago pose a challenge to the generality of the results reported here. For instance, the presence of large numbers of peripheral males may provide females with a wider choice of potential copulatory partners than would be available in the wild. When many females are in oestrus simultaneously, as commonly occurs at Cayo Santiago, high-ranking males may be less able to monopolize fertile females than in wild groups (Emlen \& Oring 1977; Barenstain \& Wade 1983). However, the risk of male attack on a female copulating with a lowranking male presumably increases with the number of males that outrank her partner, and hence with the number of males in the group. Yet severe attacks by males on oestrous females have also been observed in small wild groups (e.g. Lindburg 1971).

\section{Conclusion}

In this paper I have shown that female mate choice may be measured using purely observational data, by determining which patterns of female behaviour predict rates of potentially fertile copulations in comparisons between heterosexual dyads. In some animal species, the distribution of copulations among males closely reflects female choice, because females are free to rebuff male courtship attempts without incurring substantial costs (e.g. peafowl, Pavo cristatus; Petrie et al. 1991). But in species in which (1) male sexual coercion is suspected to influence the distribution of copulations (e.g. many primates; Smuts \& Smuts, in press), and (2) experimental manipulation in controlled settings would remove mating behaviour from its social context, reducing the generality of results, the general procedure used in this paper has wide applicability.

My results represent an addition to a growing body of evidence (reviewed in Fedigan 1983 and Small 1989; Huffman 1991) indicating that female non-human primates sometimes exercise mate choice for males other than the most dominant. Recent data from other taxa (e.g. birds; Petrie et al. 1991) suggest that male ornaments important in female choice do not always affect inter-male competitive ability. These findings contrast with widely accepted theoretical formulations (e.g. Borgia 1979) that hold or imply that inter- and intrasexual selection will tend to converge in their effects, i.e. that the same characteristics will increase both male competitive ability and male sexual attractiveness.

\section{ACKNOWLEDGMENTS}

I thank B. Gault, J. Gros-Louis, A. Lake and S. Perry for data collection. K. Hill, W. Holmes, M. Huffman, J. Mitani, S. Perry, M. Small, B. Smuts, M. West, R. Wrangham and two anonymous referees provided helpful comments on earlier drafts of the manuscript. M. Kessler of the Caribbean Primate Research Center gave permission to conduct this study. Research was supported by the Leakey Foundation, NSF (BNS-8816132) and two units of The University of Michigan: the Rackham School of Graduate Studies and the Evolution and Human Behavior Program. Cayo Santiago was supported by the University of Puerto Rico, and NIH Grant P40-RR03640-03. This study forms part of my Ph.D. thesis at The University of Michigan. Publication No. 109 of the Evolution and Human Behavior Program.

\section{REFERENCES}

Altmann, J. 1974. Observational study of behaviour: sampling methods. Behaviour, 49, 227-265. 
Altmann, S. A. 1962. A field study of the sociobiology of rhesus monkeys (Macaca mulatta). Ann. N.Y. Acad. Sci., 102, 338-435.

Berenstain, L. \& Wade, T. D. 1983. Intrasexual selection and mating strategies in baboons and macaques. Int. J. Primatol., 4, 201-235.

Borgia, G. 1979. Sexual selection and the evolution of mating systems. In: Sexual Selection and Reproductive Competition in Insects (Ed. by M. S. Blum \& N. A. Blum), pp. 19-80. New York: Academic Press.

Bradbury, J. W. \& Andersson, M. B. (Eds). 1987. Sexual Selection: Testing the Alternatives. New York: John Wiley.

Catchpole, H. R. \& van Wagenen, G. 1978. Reproduction in rhesus monkeys, Macaca mulatta. In: The Rhesus Monkey (Ed. by G. H. Bourne), pp. 118-139. New York: Academic Press.

Chapais, B. 1983. Reproductive activity in relation to male dominance and the likelihood of ovulation in rhesus monkeys. Behav, Ecol. Sociobiol., 12, 215228.

Conaway, C. H. \& Koford, C. B. 1964. Estrous cycles and mating behavior in a free-ranging band of rhesus monkeys. J. Mammal., 45, 577-588.

Drickamer, L. C. 1974. Social rank, observability and sexual behavior of rhesus monkeys (Macaca mulatta). J. Reprod. Fert., 37, 117-120.

Drickamer, L. C. \& Vessey, S. 1973. Group changing in free-ranging male rhesus monkeys. Primates, 14, 359-368.

Emlen, S. T. \& Oring, L. W. 1977. Ecology, sexual selection, and the evolution of mating systems. Science, 197, 215-223.

Fedigan, L. M. 1983. Dominance and reproductive success in primates. Yrbk phys. Anthropol., 26, $91-129$

Fedigan, L. M. \& Gouzoules, H. 1978. The consort relationship in a troop of Japanese macaques. In: Recent Advances in Primatology. Vol. I (Ed. by D. J. Chivers \& J. Herbert), pp. 493-495. London: Academic Press.

Goodall, J. 1986. The Chimpanzees of Gombe: Patterns of Behavior. Cambridge: Harvard University Press.

Gordon, T. P. 1981. Reproductive behavior in the rhesus monkey: social and endocrine variables. Am. Zool., 21, 185-195.

Halliday, T. R. 1983. The study of mate choice. In: Mate Choice (Ed. by P. Bateson), pp. 3-22. Cambridge: Cambridge University Press.

Harvey, P. H., Kavanagh, M. \& Clutton-Brock, T. H. 1978. Sexual dimorphism in primate teeth. $J$. Zool., 186, 475-485.

Heisler, L., Andersson. M. B., Arnold, S. J., Boake, C. R., Borgia. G., Hausfater, G., Kirkpatrick, M., Lande, R., Maynard Smith, J., O'Donald, P., Thornhill, A. R. \& Weissing, F. J. 1987. The evolution of mating preferences and sexually selected traits. In: Sexual Selection: Testing the Alternatives (Ed. by J. W. Bradbury \& M. B. Andersson), pp. 97-118. New York: John Wiley.

Hill, D. A. 1987. Social relationships between adult male and female rhesus macaques: I. sexual consortships. Primates, 28, 439-456.
Hinde, R. A. \& Atkinson, S. 1970. Assessing the roles of social partners in maintaining mutual proximity as exemplified by mother-infant relations in rhesus monkeys. Anim. Behav., 18, 169-176.

Hrdy, S. B. 1979. Infanticide among animals: a review, classification and examination of the implications for the reproductive strategies of females. Ethol. Sociobiol. 1, 13-40.

Huffman, M. A. 1987. Consort intrusion and female mate choice in Japanese macaques (Macaca fuscata). Ethology, 75, 221-234.

Huffman, M. A. 1991. Mate selection and partner preferences in female Japanese macaques. In: The Monkeys of Arashiyama: Thirty-five Years of Research in Japan and the West (Ed. by L. M. Fedigan \& P. J. Asquith). pp. 101-121. New York: SUNY Press.

Janson, C. H. 1984. Female choice and mating system of the brown capuchin monkey Cebus apella. $Z$. Tierpsychol., 65, 177-200.

Kaufmann, J. H. 1965. A three-year study of mating behavior in a free-ranging band of rhesus monkeys Ecology, 46, 499-512.

Kummer, H. 1968. The Social Organization of Hamadryas Baboons. Chicago: University of Chicago Press.

Lindburg, D. G. 1971. The rhesus monkey in northern India: an ecological and behavioral study. In: Primate Behavior. Vol. 2 (Ed. by L. A. Rosenblum), pp. 1-106. New York: Academic Press.

McMillan, C. A. 1989. Male age, dominance, and mating success among rhesus macaques. Am. J. phys. Anthropol., 80, 83-89.

Maghsoodloo, S. 1975. Estimates of the quantiles of Kendall's partial rank correlation coefficient. J. Stat. Comp. Simul., 4, 155-164.

Maghsoodloo, S. \& Laszlo Pallos, L. 1981. Asymptotic behavior of Kendall's partial rank correlation coefficient and additional quantile estimates. $J$. Stat. Comp. Simul. 13, 4l-48.

Malik, I., Seth, P. K. \& Southwick, C. H. 1984. Population growth of free-ranging rhesus monkeys at Tughlaqabad. Am. J. Primatol., 7, 311-321.

Manson, J. H. 1991. Female mate choice in Cayo Santiago rhesus macaques. Ph.D. thesis, University of Michigan.

Melnick, D. J., Pearl, M. C. \& Richard, A. F. 1984. Male migration and inbreeding avoidance in wild rhesus monkeys. Am. J. Primatol., 7, 229-243.

Petrie, M., Halliday, T. \& Sanders, C. 1991. Peahens prefer peacocks with elaborate trains. Anim. Behav.. 41, 323-331.

Rawlins, R. G. \& Kessler, M. J. 1986. The history of the Cayo Santiago colony. In: The Cayo Santiago Macaques: History, Behavior, and Biology (Ed. by R. G. Rawlins \& M. J. Kessler), pp. 13-45. Albany: SUNY Press.

Sade, D. S. 1967. Determinants of dominance in a group of free-ranging rhesus monkeys. In: Social Communication Among Primates (Ed. by S. A. Altmann), pp. 99 114. Chicago: University of Chicago Press.

Sade, D. S. 1972. A longitudinal study of social behavior of rhesus monkeys. In: Functional and Evolutionar. Biology of Primates (Ed. by R. Tuttle), pp. 378-398. Chicago: Aldine-Atherson. 
Sade, D. S., Cushing, K., Cushing, P., Dunaif, J., Figueroa, A., Kaplan, J. R., Lauer, C., Rhodes, D. \& Schneider, J. 1977. Population dynamics in relation to social structure on Cayo Santiago. Yrbk Phys. Anthropol., 20, 253-262.

Small, M. F. 1988. Female primate sexual behavior and conception: are there really sperm to spare? Curr. Anthropol., 29, 81-100.

Small, M. F. 1989. Female choice in nonhuman primates. Yrbk phys. Anthropol., 32, 103-127.

Small, M. F. 1990. Promiscuity in Barbary macaques (Macaca sylvanus). Am. J. Primatol., 20, 267-282.

Smuts, B. \& Smuts, R. W. In press. Male aggression and sexual coercion of females in non-human primates and other mammals: evidence and theoretical implications. In: Advances in the Study of Behavior. Vol. 22 (Ed. by
P. J. B. Slater, M. Milinski, J. S. Rosenblatt \& C. T. Snowdon). New York: Academic Press.

Takahata, Y. 1982a. Social relations between adult males and females of Japanese monkeys in the Arashiyama B troop. Primates, 23, 1-23.

Takahata, Y. 1982b. The socio-sexual behavior of Japanese monkeys. Z. Tierpsychol., 59, 89-108.

Taub, D. M. 1980. Female choice and mating strategies among wild Barbary macaques (Macaca sylvanus). In: The Macaques: Studies in Ecology, Behavior, and Evolution (Ed. by D. G. Lindburg), pp. 287-344. New York: Van Nostrand Reinhold.

Tutin, C. E. G. 1979. Mating patterns and reproductive strategies in a community of wild chimpanzees ( $P$ an troglodytes schweinfurthii). Behav. Ecol. Sociobiol., 6, 29-38. 